\title{
Utility-scale photovoltaic generators: a review on trends, grid code requirements and challenges
}

\author{
Nadia M. L. Tan ${ }^{1}$, Agileswari K. Ramasamy ${ }^{2}$, Vigna K. Ramachandaramurthy ${ }^{3}$, \\ Marayati Marsadek ${ }^{4}$, Mohd. R. Othman ${ }^{5}$, Ibrahim Ariffin ${ }^{6}$ \\ ${ }^{1,2,3,4}$ Department of Electrical and Electronics Engineering, Universiti Tenaga Nasional (UNITEN), Malaysia \\ ${ }^{3,4}$ Institute of Power Engineering (IPE), UNITEN, Malaysia \\ ${ }^{5,6}$ Grid Solution Expertise Department, Tenaga Nasional Berhad, Malaysi
}

\begin{tabular}{l}
\hline \hline Article Info \\
\hline Article history: \\
Received Aug 19, 2019 \\
Revised Oct 21, 2019 \\
Accepted Nov 5, 2019 \\
\hline Keywords: \\
Dynamic voltage support \\
Fault-ride-through \\
Grid code \\
Grid connection requirements \\
Large-scale solar \\
Low-voltage ride-through \\
\hline
\end{tabular}

\begin{abstract}
This paper provides an overview of the global trends in utility-scale photovoltaic (PV) installed capacity. This paper also presents a comparison of grid-connection requirements of six countries in the continents of Europe, Asia, Africa, and Australia for utility-scale PV generators in normal and abnormal grid conditions. Many country-based grid codes and international standards (IEEE 1547) for interconnection of inverter-based renewable energy generators are demanding stricter grid-connection compliance from utility-scale PV generators to ensure power system safety and reliability as its penetration level increases. This paper then discusses the economic and technical impacts, and explores the preparedness of PV generation systems in meeting the grid code requirements.
\end{abstract}

Copyright $\odot 2020$ Institute of Advanced Engineering and Science. All rights reserved.

Corresponding Author:

Nadia M. L Tan,

Department of Electrical and Electronics Engineering,

Universiti Tenaga Nasional, Malaysia.

Email:nadia@uniten.edu.my

\section{INTRODUCTION}

There is a strong demand for renewable energy (RE) generation globally. Several factors that are causing the strong demand are (i) unsustainable nature of fossil fuel supply, (ii) significant price decline in several RE technologies (particularly wind and PV technologies), and (iii) the advancements of energy storage technologies, as published in [1, 2]. In 2016, the accumulated global RE installed capacity, which includes ocean and geothermal power, PV, concentrated solar power (CSP), and wind, installed at distribution and transmission networks, is as-high-as $921 \mathrm{GW}$. Based on the $921 \mathrm{GW}$ of RE installed capacity, wind energy has the largest share $(487 \mathrm{GW})$, followed by PV (303 GW), bio-power (112 GW), geothermal power $(13.5 \mathrm{GW})$, and CSP $(4.8 \mathrm{GW})$. Wind and PV generators are also known as inverter-based generators.

In 2016, there were $76 \mathrm{GW}$ of new PV installations and $72 \%$ of those new installations were utilityscale PV systems that are connected to transmission networks [3]. Utility-scale PV systems are typically ground-mounted, grid-tied, and of multi-MW in rating. The increasing presence of these inverter based generators can pose power system stability problems because they have low inertia and the source is intermittent in nature. Moreover, with increasing penetration of the multi-MW PV generators, it becomes necessary for the generators to have low voltage ride-through (LVRT) capability because disconnection of the generators under low-voltage (LV) conditions can further deteriorate power system stability. Therefore, grid system operators (GSOs) from many countries such as Germany, Great Britain, Australia, Denmark, and etc. Are adapting their grid codes to accommodate the change in generation mix in the power system while maintaining the grid stability, security and reliability. Inverter-based generators, in those countries, are 
no longer expected to only supply active power during a normal grid condition, they are also expected to have

LVRT capabilities and are required to provide static and dynamic grid-voltage-support during a grid-fault condition [4-5]. While the grid connection codes for inverterbased generators including utilityscale PV generators are fairly recent, distribution connection codes for distributed generators (DGs) have a longer history. Prior to 2015, electrical standards for the distribution systems such as the IEEE 1547 lack LVRT and dynamic voltage support requirements. The recent IEEE Standards 1547-2018 recommends three categories of LVRT requirement that differs based on the different trip setting times and stipulates dynamic voltage support through the voltage/power requirements for DGs that are connected to electric power system, in abnormal grid conditions [6].

Grid-connection codes for inverter-based generators of different countries varies due to the distinct characteristics of the power system network in each country and the grid codes are becoming stricter by requiring that inverter-based generators provide ancillary services, e.g. fault-ride-through (FRT) capability, active and reactive power control, and voltage and frequency support, to ensure similar performances as conventional power generators. A comparison of grid connection codes for China, Germany, US-Puerto Rico, Romania, and South Africa in terms of FRT requirements showed that the grid code of US-Puerto Rico is the strictest as PV inverters are required to withstand zero voltage at the point of common coupling (PCC) for as-long-as $600 \mathrm{~ms}$ [7].

There is only a few comparisons of grid connection codes that emphasizes on LVRT capability and ancillary services for PV generators during normal and abnormal grid conditions. However, grid-connection codes are constantly being revised to suit changing power system network conditions with RE. Therefore, reviews and analyses of the grid codes are still necessary to update and improve understanding of the best practices in grid connection codes. There is also a need to understand the challenges of utility-scale PV generators in complying with grid codes, including their technological readiness.

This paper aims to compare the latest grid-connection codes for utility-scale PV generators. It also aims to discuss the technological readiness of PV generator systems in complying with grid codes in abnormal grid conditions. This paper is organized such that section II describes the trends in utility-scale PVgenerators installed capacity. Following that, section III compares the grid connection requirements for utility-scale PV generators for six countries of four continents with focus on voltage, frequency, power factor and THD requirements, active power and frequency control, and FRT requirements. In section IV the paper describes the challenges and technological readiness of grid-integrated utility-scale PV generation systems. Finally, the conclusions are drawn in Section V.

\section{TRENDS IN UTILITY-SCALE PV-GENERATOR INSTALLED CAPACITY}

Figure 1 presents a ten-year trend (2006 to 2016) in global cumulative installed capacity of wind and PV generators. In 2006, the total installed capacity of wind generation was 12 times more than the installed capacity of PV generators, with the US and European countries (Spain, Germany, France, Italy, Portugal) dominating wind generation [8]. However, the accumulated wind ( $487 \mathrm{GW}$ ) installed capacity reduced to 1.6 times the accumulated PV (303 GW) installed capacity in 2016. Considering existing policies and measures, with "business-as-usual" scenario, the trend in accumulated installed capacity of wind and PV generation can be extrapolated to show that installed capacity of PV generators will draw with wind generation in 2025 . Many factors can affect the increase in PV installed capacities. Among others, low power purchase agreement (PPA) prices $(\$ / \mathrm{kWh})$ of PV in countries like Peru, South Africa, Zimbabwe, and India, which has been decreasing exponentially since 2009. In India and the UAE, the cost of PPA for wind and PV generators are almost the same in 2016 [3]. Such rapid decrease in cost of PV increases the competitiveness of PV generation.

Figure 2 overviews the distribution of accumulated PV installed capacity globally $(306.5 \mathrm{GW})$ in year 2016, which is an increase by 50\% (76.6GW) in 2015 [3]. The cumulative PV installed capacity in AsiaPacific countries is the largest globally at 147.2GW. Apart from China and Japan, other countries that contributed to this high amount of PV installed capacities in Asia Pacific include India, South Korea, and Australia [3]. In Southeast Asia, Thailand is leading the PV generation market [9] with a total PV installed capacity of $2.17 \mathrm{GW}$, while Malaysia aims to increase its PV installed capacity from the current $335.77 \mathrm{MW}$ via additional $1 \mathrm{GW}$ of utility-scale PV by 2020 [10]. The next highest cumulative PV installed capacity is in Europe (Germany, Italy, UK, France, and Spain) at 104GW. The American continent (including North, Central and South America) follows after Europe and recorded about $46 \mathrm{GW}$ of cumulative PV installed capacity. The leading countries in America for PV generation include US, Puerto Rico, Honduras, Costa Rica, Nicaragua, and Uruguay [11-12]. The development of PV generation in the Middle-East and African continent (countries including Kenya, Senegal, Ghana, and Uganda) is quite low, where its cumulative 
installed capacity is $4.7 \mathrm{GW}$ [3]. Egypt is targeted to become the leading PV generator in Africa with good political support prospects [13]. In the rest of the world the total installed capacity of PV is 4.6GW.

Figure 3 shows the top five countries with PV-generation in 2016. They are China, Japan, Germany, US, and Italy [1, 2, 14-15]. The PV installed capacity accumulated by the top five countries accounts for up to $85 \%$ of the global accumulated PV installed capacity [16]. China has the highest PV installed capacity for two consecutive years with PV installed capacity of $44 \mathrm{GW}$ and $77 \mathrm{GW}$ in 2015 and 2016, respectively. Although China is currently a leader in PV generation, PV is only 5\% of China's total generation capacity, and PV generation is ranked third after thermal generation using sources from coal and oil [17]. Japan surpassed Germany as having the second highest PV installed capacity in the world at 43 GW. However, PV constitutes only $4.8 \%$ of the total generation capacity in Japan, ranking as the sixth among generation of various sources in the country [18-19]. Even though Germany has the third largest PV installed capacity (41 GW) globally, PV generation is ranked as the second highest generation at $21.4 \%$ of the total installed capacity in the country [20]. PV installed capacity is only a small fraction of the total generation capacity in the US and Italy, where it is $1.9 \%$ and $7.8 \%$, respectively.

It can be seen from the global trends that utility-scale PV is growing year-on-year with China, Japan, Europe and the US leading the market. However, many other countries globally are also aiming to increase their PV installed capacity, leading to changes to the grid-connection codes for inverter based generators in normal and abnormal grid conditions. The following sections compare the grid connection code for inverterbased generators including utility-scale PV, discussing the requirements in normal and abnormal grid conditions such as under- and over-frequency, LV conditions and others.

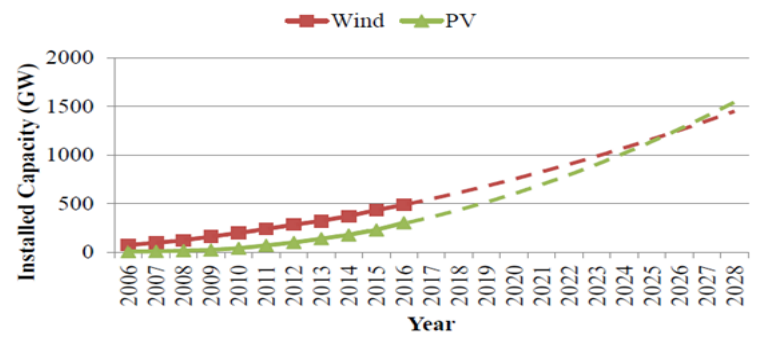

Figure 1. Trend in installed capacity for wind and PV generators from year 2006 to 2016 [1]

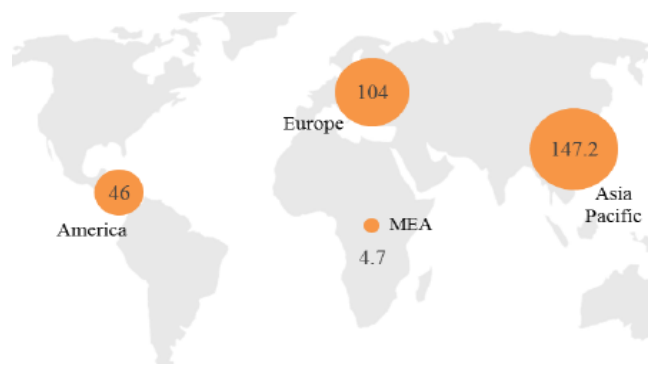

Figure 2. Worldwide distribution of cumulative PV installed capacities in 2016

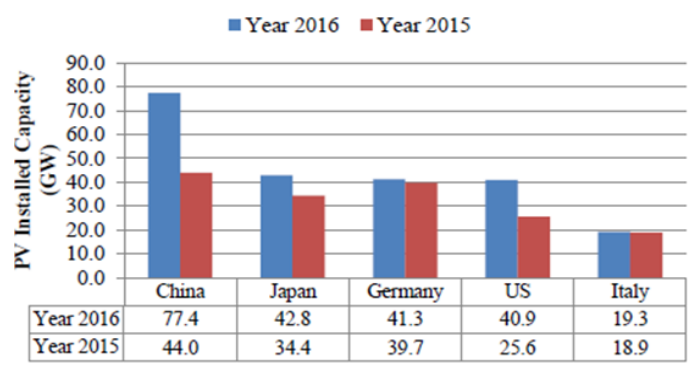

Figure 3. Top five countries with the highest PV installed capacity in year 2016

\section{COMPARISON OF GRID-CONNECTION REQUIREMENTS FOR ULTILITY-SCALE PV GENERATORS}

This section compares the grid-connection requirements specifically for utility-scale PV generators in Germany, United Kingdom (UK), Australia, Denmark, Egypt, and Malaysia. During normal grid conditions, grid-connection codes specify operating voltage, frequency, and power factor range, and the total harmonics distortion (THD) requirements for PV generators or inverter-based generators. During abnormal grid conditions, active power and frequency control, and fault-ride-through requirements are specified. Table 1 summarizes the available requirements for inverter-based generators that are specified in the gridconnection codes of the six countries. It also shows the reference for the grid-codes pertaining to this paper [22-27]. Note that, grid connection codes differ from one country to another depending on individual grid characteristic and strength. 
Table 1. Available Grid Connection Specifications for PV Generators in Various Countries

\begin{tabular}{|c|c|c|c|c|c|}
\hline \multirow[t]{2}{*}{ Country } & \multirow[t]{2}{*}{ VFPTR $^{a}$} & \multirow[t]{2}{*}{$\mathrm{APFC}^{b}$} & \multicolumn{2}{|c|}{ FRTR $^{c}$} & \multirow{2}{*}{$\operatorname{Re}$} \\
\hline & & & $\mathrm{LVWC}^{d}$ & DVSC $^{e}$ & \\
\hline Germany & $\checkmark$ & $\checkmark$ & $\checkmark$ & $\checkmark$ & [22] \\
\hline UK & $\checkmark$ & $x$ & $\checkmark$ & $x$ & [23] \\
\hline Australia & $\checkmark$ & $x$ & $\checkmark$ & $x$ & [24] \\
\hline Denmark & $\checkmark$ & $x$ & $\checkmark$ & $\checkmark$ & [25] \\
\hline Eygpt & $\checkmark$ & $\checkmark$ & $\checkmark$ & $\checkmark$ & [26] \\
\hline Malaysia & $\checkmark$ & $\checkmark$ & $\checkmark$ & $x$ & [27] \\
\hline
\end{tabular}

${ }^{a}$ Voltage, frequency, power factor, and THD requirements. ${ }^{b}$ Active power and frequency control ${ }^{c}$ Fault-ride-through requirements. ${ }^{d}$ Low-voltage withstand capability.

${ }^{e}$ Dynamic voltage support capability.

\subsection{Voltage, Frequency, Power Factor, and Total Harmonics Distortion (THD) Requirements}

This subsection compares the grid-connection requirements during normal condition for different countries, which include the comparison of frequency and voltage range, power factor range, and the acceptable voltage $\mathrm{THD}_{\mathrm{v}}$ injected by the inverter-based generators, in normal grid conditions. Table 2 presents the voltage and frequency range in normal grid condition of Germany, UK, Australia, Denmark, Egypt, and Malaysia. The nominal grid frequency for these countries is $50 \mathrm{~Hz}$. In UK and Malaysia, the normal grid frequency range is from $49.5 \mathrm{~Hz}$ to $50.5 \mathrm{~Hz}$. In Germany and Australia, the normal grid-frequency range is from $49.8 \mathrm{~Hz}$ to $50.2 \mathrm{~Hz}$. In Denmark and Egypt the upper frequency limit in normal grid condition is $50.2 \mathrm{~Hz}$ while no lower frequency limit was specified. Table 2 also shows that the allowable range of normal operating grid voltage of the six countries is $\pm 10 \%$ for high-voltage (HV) grids and $\pm 5 \%$ for extra-high-voltage (EHV) grids. Germany specifies its voltage range as $96 \mathrm{kV}$ to $123 \mathrm{kV}$ around the nominal voltage of $110 \mathrm{kV}$, slightly more than $\pm 10 \%$ of a typical voltage limit. The lower limit of a normal grid voltage in Egypt is allowed to drop to $-15 \%$ of the nominal voltage, which is thus far the largest acceptable voltage deviation among the six countries. Note that, the voltage level at the PCC depends on the size of the installed capacity. In Egypt, PV plants above the size of $20 \mathrm{MW}$ should be connected to voltage levels above $33 \mathrm{kV}$. In Malaysia, aggregated utility-scale PV generators between $30 \mathrm{MW}$ and $50 \mathrm{MW}$ are required to be connected to the transmission network $(\geq 132 \mathrm{kV})$ via one interconnection point [28].

An inverter-based generator should control the power factor and THD within the range specified by the GSOs. Power factor at the point of common coupling (PCC) of inverter based generators can fluctuate due to the harmonics injection when the generators are not subjected to any control. It is best to operate the generators near to unity power factor. This is because a high power factor improves system efficiency and the power quality supplied to loads. Table 2 shows that UK, Australia, and Egypt have strict power factor requirement to ensure good power quality. Nonetheless, power factor range as specified in the South African grid code is stricter because it requires the range to be maintained from 0.975 lagging to 0.975 leading [7]. The limits of harmonics injection have been specified in several grid codes. Countries including Australia, Denmark, and Malaysia highlighted that the total voltage harmonics distortion $\left(\mathrm{THD}_{\mathrm{v}}\right)$ under transmission levels should be less than 3.0\%. Both Australia and Denmark list the percentage of harmonics voltage for harmonics number 2 to 40 . Germany does not outline the THD, but mentioned that the harmonics current fed by inverter-based generators should not exceed the limits for ordinal harmonics between 5 and 40 [22]. There is also no THD specification in the UK grid code. The Egyptian grid code only mentioned that the harmonics settings should follow that of IEEE 519-1992, and it is believed that the maximum $\mathrm{THD}_{\mathrm{v}}$ is $2.0 \%$ [29].

Table 2. Frequency, Power Factor and Voltage Range in Normal Grid Conditions

\begin{tabular}{|c|c|c|c|c|c|c|c|}
\hline Country & & Germany & UK & Australia & Denmark $^{a}$ & Egypt & Malaysia \\
\hline $\begin{array}{c}\text { Normal } \\
\text { Operating } \\
\text { Frequency }\end{array}$ & {$[\mathrm{Hz}]$} & $50 \pm 0.2$ & $50 \pm 0.5$ & $50 \pm 0.2$ & $\begin{array}{l}-b \text { to } \\
50.2\end{array}$ & ${ }^{c}{ }^{c}$ to 50.2 & $50 \pm 0.5$ \\
\hline $\begin{array}{l}\text { Nominal } \\
\text { Voltage at } \\
\text { PCC }\end{array}$ & {$[\mathrm{kV}]$} & 110 & $\geq 132$ & $\geq 66$ & $\geq 100$ & $>33$ & $\geq 132$ \\
\hline $\begin{array}{c}\text { Normal } \\
\text { Operating } \\
\text { Voltage }\end{array}$ & {$[\mathrm{kV}]$} & $\begin{array}{c}+12 \% \text { and } \\
+13 \%\end{array}$ & $\begin{array}{l}275 \pm 10 \% \\
132 \pm 10 \%\end{array}$ & $\begin{array}{c}400 \pm 5 \% \\
\pm 10 \%\end{array}$ & $\pm 10 \%$ & $\begin{array}{c}+10 \% \text { and } \\
-15 \%\end{array}$ & $\begin{array}{c}500 \pm 5 \% \\
275 \pm 10 \% \\
132 \pm 10 \%\end{array}$ \\
\hline Power Factor & Leading & 0.925 & 0.95 & 0.95 & 0.9 & 0.95 & 0.85 \\
\hline & Lagging & 0.95 & 0.95 & 0.95 & 0.9 & 0.95 & 0.95 \\
\hline Voltage THD & {$[\%]$} & $x$ & $x$ & $<3.0$ & $<3.0$ & $<2.0$ & $<3.0$ \\
\hline
\end{tabular}

Indonesian J Elec Eng \& Comp Sci, Vol. 18, No. 2, May 2020 : 573 - 585 


\subsection{Active Power and Frequency Control in Abnormal Grid Conditions}

Fluctuations in power systems frequency occurs when there is a power imbalance in the grid. Table 3 presents the grid frequency limits based on the grid codes of the six countries under review. If the power system frequency is outside the normal operating frequency range shown in the table, the system is said to be experiencing under- or over-frequency. Outside the normal operating frequency, the minimum frequency can be as-low-as $47 \mathrm{~Hz}$ and the maximum frequency can be as-high-as $52 \mathrm{~Hz}$ in countries such as UK, Australia, Denmark, and Malaysia. However, the generators are required to immediately disconnect when the power system frequency is outside the lower and upper limits.

In an under frequency condition, GSOs are alerted when the frequency reaches $49.8 \mathrm{~Hz}$ (Germany and Australia) or $49.5 \mathrm{~Hz}$ (UK and Malaysia). Before the system frequency violates the under-frequency range, GSOs typically require synchronous generators to participate in primary frequency control a few seconds after power imbalance occurs. For large imbalances, under-frequency load shedding are also activated. In Germany, a 5-step load shedding plan is employed as a form of power systems defence during a high power imbalance [22, 30]. The increasing penetration of utility-scale PV generators that replace synchronous generators can reduce power systems inertia and the system's capability in frequency regulation, which will affect power system frequency stability. Unlike the wind turbines, no grid codes have subjected PV generators to participate in under-frequency response. The authors of [31] have studied the effectiveness of utility-scale PV in fast frequency response control by operating PV generators below its maximum power so that the generators can inject the reserved power during an under-frequency frequency event. Nevertheless, a combination of large-scale PV generators with energy storage is considered to be more reliable in frequency response control than PV generators alone.

GSOs are alerted when the frequency reaches $50.2 \mathrm{~Hz}$ (in Germany, Denmark, Australia, and Egypt) or $50.5 \mathrm{~Hz}$ (in UK and Malaysia), which is known as an over-frequency condition. The $50.2 \mathrm{~Hz}$ problem in Germany (in LV network) is a result of high penetration of PV generators that were required to disconnect when the system frequency reached $50.2 \mathrm{~Hz}$, which stressed the primary frequency controllers in the system [33]. After the incident, gradual active power reduction in response to frequency increment is required in the German grid code. All generators, synchronous or inverter based, shall be operated with temporary active power output limiting in the cases of over-frequency, and the reduction rate differ from one grid code to another [22-27, 34]. Note that, a standard rate of active power reduction cannot be implemented due to distinct grid characteristic and different power-system inertia in each country. This rate of active power reduction is commonly expressed in terms of ratio between the changes in active power to the change in frequency.

Figure 4 shows the relationship between active power output and grid system frequency for Germany, Egypt, and Malaysia. The grid codes for UK, Australia, and Denmark did not display the graph or mention the details of active power output control due to system frequency deviation. In both Germany and Egypt, power plants are required to curtail their active power by a gradient of $40 \%$ of instantaneous nominal active power per Hertz when the system frequency is greater or equal to $50.2 \mathrm{~Hz}$ [22, 26, 35]. Both countries have the same active power reduction gradient. When system frequency is $51.5 \mathrm{~Hz}$, the PV generators should cease to supply active power immediately. In Germany PV generators above $100 \mathrm{MW}$ in installed capacity are required to participate in the over-frequency control. In Egypt, generators above the size of $50 \mathrm{~kW}$ are required to abide to its over-frequency control requirement. The Malaysian grid code specifies that the active power output of PV generators should be curtailed by a gradient of $40 \%$ of instantaneous nominal active power per Hertz. However, the active power curtailment starts at $50.5 \mathrm{~Hz}$ up to the frequency limit of $52 \mathrm{~Hz}$. The Malaysian grid code does not specify the minimum size of generators that should take part in overfrequency control.

Table 3. Grid Frequency Limits in Abnormal Grid Conditions

\begin{tabular}{lcccccc}
\hline Country & Germany & UK & Australia & Denmark & Egypt & Malaysia \\
\hline Grid frequency limits $[\mathrm{Hz}]$ & 47.5 to 51.5 & 47.0 to 52.0 & 47.0 to 52.0 & 47.0 to 52.0 & 47.5 to 51.5 & 47.0 to 52.0 \\
\hline
\end{tabular}

\subsection{Fault-Ride-Through (FRT) Requirements}

Before FRT requirements were introduced to include RE generators, several countries with high penetration of wind energy such as Germany, China and Australia have experienced power instability issues in many grid-connected renewable plants, which were caused by faults in the grid [36-37]. During a grid fault, the voltage of the faulted-phase sags due to low impedance on the transmission network, which effect can propagate across wide areas until the fault is cleared. Without LVRT requirements, a large amount of RE generators will disconnect due to the voltage sag and produces an imbalance between generation and load, further deteriorating grid stability [36]. If the rate of change of frequency (RoCoF) of the power systems is 
too fast for under-frequency load shedding to take place, the grid fault may even cause power outages as experienced in South Australia in September 2016 [37].

Grid codes have been revised to include FRT requirements of grid-connected RE generators, which includes PV [21, 27]. The FRT requirements specify the duration in which PV plants should stay connected to the grid in case of a fault that can cause a voltage sag (or under-voltage) or a voltage swell (or overvoltage). This section compares grid codes having LVRT and voltage-support requirements for RE generators including PV generators.

\subsubsection{Low-Voltage Withstand Capability}

The LVRT requirements of all grid codes reviewed in this section are the same for symmetrical and asymmetrical faults. However, Germany's grid code distinguishes the LVRT requirements for three-phase symmetrical and two-phase asymmetrical faults. Moreover, during single-phase faults, generators are not allowed to disconnect unless as a reaction to network protection.

Figure 5 presents the LVRT requirements of PV generators in Germany, Australia, Egypt, UK, Denmark, and Malaysia. The voltage in per unit represents the line-to-line root-mean-square (RMS) voltage at the PCC. PV generators have to remain connected to the grid in the regions above the curves and can disconnect in the regions below the curves. The duration that PV generators should remain connected when the voltage at the PCC is zero (three-phase symmetrical fault to ground) is $150 \mathrm{~ms}$ in Germany and Malaysia, $140 \mathrm{~ms}$ in UK, $250 \mathrm{~ms}$ in Egypt, and $450 \mathrm{~ms}$ in Australia. In US-Puerto Rico, the withstand capability during a three-phase symmetrical fault to ground is as long as $600 \mathrm{~ms}$ [7]. Fault clearing time can also be obtained from the LVRT curves. In Germany, UK, and Denmark, the safe voltage limit of 0.85 p.u. should be reached in $3 \mathrm{~s}$ and $2.5 \mathrm{~s}$, and $1.5 \mathrm{~s}$, respectively. In Malaysia and Egypt, the safe voltage limit is 0.9 p.u. and that is should be reached in $1.5 \mathrm{~s}$ and $5 \mathrm{~s}$ after the severest fault occurrence. However, in Australia, all faults leading to a voltage sag of $20 \%$ to $100 \%$ should be cleared in $450 \mathrm{~ms}$ at the safe voltage limit of 0.8 p.u.

The grid code for PV generators was published in Germany (Transmission Code 2007 [38]) in August 2007 by Verband der Netzbetreiber (VDN) for symmetrical faults. It stipulates network and system rules of the German Transmission System Operator. In year 2015 and 2017, VDN had also published the second [22] and drafted the third [39] amendments of the technical requirements, respectively. Figure 6 compares the LVRT requirements of asynchronous generators in Germany based on the grid codes of version 2015 and 2017, which includes the LVRT curves for asymmetrical and symmetrical faults. The duration that a PV generator should be connected to the grid in a two-phase short circuit is longer than the duration in a three-phase short circuit. During an FRT event, the PV generators are not only required to stay connected and continue to inject active current, the generators are also required to prioritize reactive current injection as will be discussed in the following subsection [21, 40, 41-45].

\subsubsection{Dynamic Voltage Support Capability}

Traditionally, PV generators unlike thermal generators do not participate in dynamic voltage support as they are typically connected at the distribution level. However, this has evolved with the increased penetration of DGs and utility-scale wind and PV generators. The IEEE 1547-2018 [6] and many grid codes [22-27] now require dynamic voltage support from DGs at the distribution and transmission network level, respectively. Additional reactive current injection for dynamic voltage support is carried out based on a gain factor commonly known as the $k$-factor [22, 25-26].

During a fault, injection of reactive current for dynamic voltage support from PV generators should be prioritized. Figure 7 presents the reactive current injection requirements for Germany, Egypt, and Denmark [22, 25-26]. A voltage dead-band is present for voltage variation of \pm 0.1 p.u., where no injection of reactive current for dynamic voltage support is needed in the normal voltage range of 0.9 to 1.1 p.u. Outside of the deadband, additional reactive current $\Delta i_{\mathrm{B}}$ is injected proportional to the change in voltage $\Delta u$ at the PCC. The gain factor $k$ is typically from 2 to 6 , based on the requirements of GSOs. When voltage support is required, capacitive reactive current is injected at the PCC. However, when voltage limitation is required, inductive reactive current is injected at the PCC. Note that, in Denmark, injection of reactive current is only for dynamic voltage support. There are grid codes with no specific $k$-factor for reactive current injection. Instead, in UK and Malaysia, the injection of active current is at least in proportion to the retained balanced voltage at the PCC. Moreover, the reactive current injection should be maximum without exceeding the transient power limits of the generators. In Australia, capacitive reactive current injection is required for dynamic voltage support during fault events. 


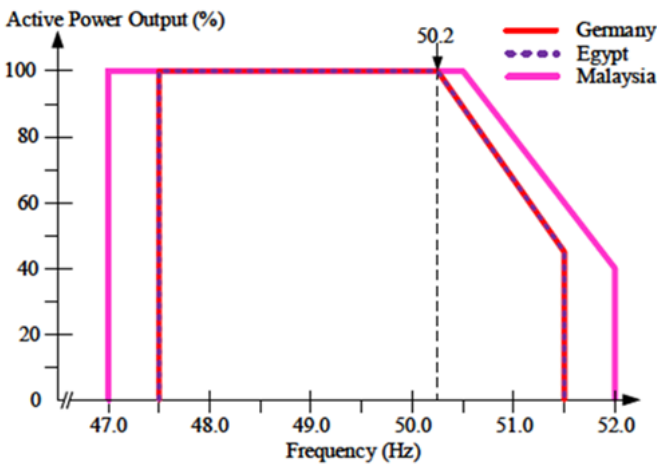

Figure 4. Active power reduction curve in Germany, Egypt, and Malaysia

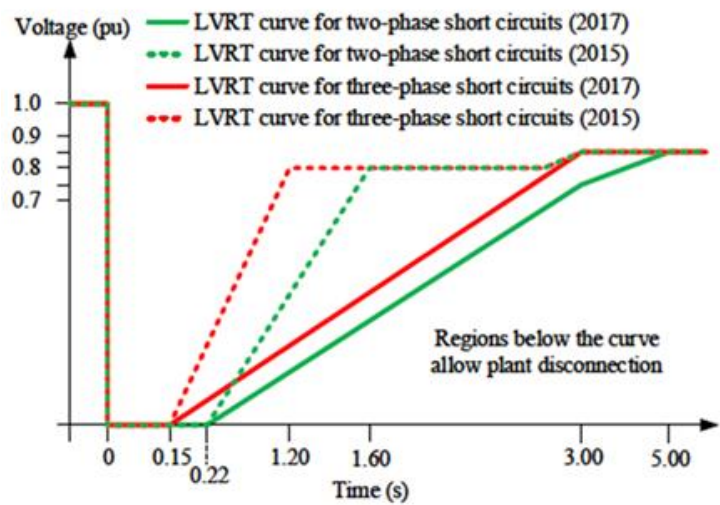

Figure 6. Comparison of LVRT curves of Germany PV plants from 2015 to 2017

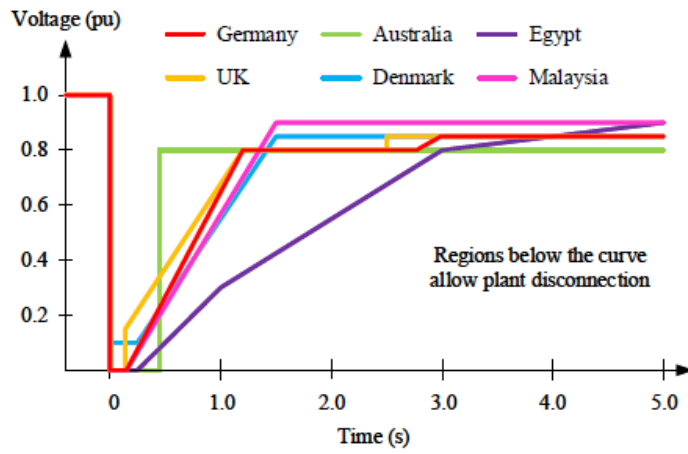

Figure 5. Comparison of LVRT curves for PV plants in six countries

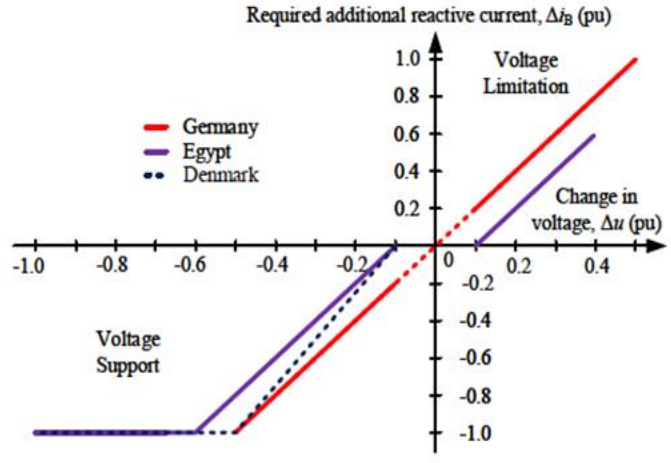

Figure 7. Comparison of reactive current injection capability for Germany, Egypt, and Denmark

The type of fault determines the type of voltage sequences appearing in the grid. While only positive-sequence voltage exists in a symmetrical grid fault, there are positive-, negative-, and possibly zerosequence voltages in an asymmetrical grid fault. Many grid codes do not have a special requirement for injection of negative-sequence reactive current during LVRT events [46]. Moreover, large-scale DGs prefer to set the negative-sequence current supply to zero, where threephase positive-sequence active or reactive currents supplied from a DG to the grid are generally kept within its rated current [47]. However, when only positive-sequence reactive current is injected, it results in over-voltage in the healthy phase during an asymmetrical grid fault. Therefore, in the Egyptian grid code, reactive current cannot be injected into the PCC in an asymmetrical grid fault. Nevertheless, since 2015, the injection of positive- and negative sequence reactive current is specified in the German grid code. It has been found that the injection of positive- and negative-sequence current at the PCC can prevent overvoltage in a healthy phase, and it produces fault responses similar to that of a synchronous generator, while increasing voltage symmetry [48].

Grid codes usually permit active current to be sufficiently reduced in favor of reactive-current injection to prevent the current rating of inverter-based generators from being violated. If the active current was reduced during the LVRT, then it should be increased as quickly as possible to its pre-fault value or maximum active current. This requirement is known as active power ramp-up rate. In the German grid code, active current should be increased at the rate of at least $20 \%$ of the rated current per second at the end of fault. The ramp-up rate value is defined in the Danish and Australian grid codes as $100 \mathrm{~kW}$ per second (equivalent to $0.1 \mathrm{MW} / \mathrm{sec}$ ) and $10 \mathrm{MW}$ per minute (equivalent to $0.1667 \mathrm{MW} / \mathrm{sec}$ ), respectively. In Malaysia, the ramp-up rate value is not provided, but instead the GSO shall specify the requirements, depending on the generation requirements. Australia is seemingly with the fastest active power ramp-up rate. This could be due to a high penetration of renewable energy, where bringing back active power supply is necessary within the shortest period to prevent frequency instability. 


\section{CHALLENGES AND TECHNOLOGY READINESS OF GRID-INTEGRATED UTILITY- SCALE PV GENERATION SYSTEMS}

With the increasing penetration of utility-scale PV generators, there is a need to study, identify, and address possible economic and technical impacts. The intermittent and variable output of PV produces economic challenges in grid interconnection of PV generators because it increases the need to use and retain conventional fossil-fuel generators [49-52]. An economic despatchability of PV generators can be improved through several methods including better PV availability forecasting [53], balancing demand and generation over a large area through transmission coordination or spatial diversity of PV generators [54], demand response, and energy storage [55, 56]. PV generation also needs careful choice of system and control architectures to meet the technical challenges of the ever increasing demands of grid codes for inverter-based generators.

Figure 8 shows that PV inverters can be connected as (a) conventional centralized inverters or (b) decentralized multistring inverters, (i) single-stage power conversion and (ii) two-stage power conversion [57, 58]. Topology in Figure 8 (b) (ii) is a more suitable choice for utility-scale PV because of its high energy harvest [59], modularity, and simple maintenance, albeit a higher system cost. As discussed in Section 3, utility-scale PV generation systems need to meet grid code requirements by operating within the steady-state voltage, frequency and power-factor limits in normal grid conditions. The PV generators also need to participate in active-power and frequency controls, have low-voltage-withstand capability, and provide dynamic voltage support in abnormal grid conditions.

PV generators typically operates at its maximum-power point to optimize its energy production. As it is a static generator, it faces the problem of having lack of inertia that rotating synchronous generators have. When more PV generators displace the conventional synchronous generators, power systems may have the challenge of frequency control through balancing of generation and demand. Over-frequency can occur due to over-generation of PV during peak solar insolation and not being able to turn-off sufficient thermal generation. On the contrary, when solar insolation reduces after sun set, sufficient generators need to be prepared to ramp-up active power to meet evening load demand [60]. When under-frequency occurs in a power systems with high PV penetration, PV generators operating at its maximum power-point will not have additional active output power to supply to the grid. PV generators also do not have the kinetic energy to compensate the initial difference between generation and load demand, which can result in an initial high RoCoF that can cause power systems instability before primary frequency response is activated between 5$30 \mathrm{~s}$ after the system frequency drops below the lower limit of the normal frequency range [31].

Several solutions have been investigated for frequency control in power systems with high PV penetration. Over generation can be overcome by curtailing PV output power [49, 61]. Other possible solutions for excess PV generation is to implement energy storage or load dumping using resistor banks [62]. However, PV output power curtailment and load dumping can result in loss of revenue. Besides that, utility companies also need to invest in generators that are capable of fast ramp-rate, e.g. gas-fired reciprocating engines or simple cycle combustion turbines, as they can function as spinning reserves to meet the required active power ramp-rate when PV is unavailable [60]. Nevertheless, increasing fossil fuel generating plants as spinning reserves tend to negate the effect of greenhouse gases $(\mathrm{GHG})$ reduction from PV generators. In overcoming under-frequency control, apart from using utility scale energy storage such as sodiumsulphide and Lithium-ion batteries, authors of [31] has proposed operating PV generators below their maximum operating point, to support system frequency in the first few seconds after system abnormality using the so called "reserved power". However, the effective margin of power reserve for PV generators operating below its maximum-power-point will vary hourly and eventually this method is still best supported by energy storage systems [32] or improved output power forecasting techniques to ensure system reliability.

Typically, PV generators would supply maximum active power in order to maximize the returns on generation, while an amount of reactive power is supplied in order to maintain the power factor at the PCC as required by the GSOs in steady-state conditions. Static synchronous compensators (STATCOMs) have traditionally been employed as voltage and current controllers in transmission grid [63]. However, with the stricter requirements of grid codes in many countries, PV generators are to remain connected to the grid and dynamically support system voltage via injection of positive- and/or negative-sequence (Germany) reactive current. Therefore, inverters and controllers in the generation systems should be ready for those technical challenges including LV rapid detection, phase angle detection, and communication capability [50, 31], and [64]. Typical PV inverters (Figure 8) are 1000 / 1500 Vdc two-level three-phase inverters or neutral-point clamped inverters, which have a low ac output voltage that are then stepped up to medium-voltage by a linefrequency transformer within the generator plant area [65] and have controllers capable of meeting grid code requirements.

Utility-scale PV inverter capacity is increasing towards the multi-MW level. Many researchers are investigating into multilevel inverters with high-frequency galvanic isolation at the dc-dc converter side, thus 
eliminating the need of LV/MV line-frequency transformers. Figure 9 presents the utility-scale PV system based on a modular multilevel single-delta bridge cell (SDBC) inverter connected directly to a mediumvoltage bus [66]. The modular multilevel SDBC inverter intended for utility-scale PV was presented with theoretical and experimental verification on LVRT capability and dynamic voltage support following the German grid code [67]. Injection of only positive-sequence and positive-plus-negative-sequence reactive current injection following the German grid code were shown to be feasible without causing any instability in the multilevel inverter. As shown in Figure 9, many strings of PV modules, which can span a large area, are connected to each of the dc-dc converters. As a consequence, imbalance of power generation can occur in any PV sub-converter and any phase due to non-uniform cloud or shading, unequal panel temperature, manufacturing tolerance, and PV module degradation and soiling [53, 67]. Current technology on control of multilevel inverters has been shown capable of meeting the requirements of grid codes on producing balanced three-phase output current in steady-state condition [68, 69]. The dc-dc converter in the modular multilevel converter for utility-scale PV generators can provide maximum-power-point-tracking (MPPT) and galvanic isolation functions to prevent the problems of leakage current between the PV panels and the converters [70] and to increase the power density of the PV generators.

\section{FUTURE SCENARIOS AND CONCLUSION}

Utility-scale PV penetration is increasing globally and looks set to have a more prominent presence in electricity generation. This renders many countries to update their grid codes to include operating requirements of PV generators during norma and abnormal grid conditions. The review of grid codes of Germany, UK, Australia, Denmark, Egypt and Malaysia provided an understanding on the requirements among others, active power and frequency control, fault ride-through capability and dynamic voltage support. It isclear that PV generators needs to provide more than just PV active power to the grid. Indeed there are many challenges faced by PV generators due to its intermittent nature in providing output power and lack of inertia. which can be costly to the generators and the power grid. Nevertheless, the PV inverters can easily provide dynamic voltage support and reactive power to the grid. The current technology of inverters and controls including energy storage systems are viewed as able to support utility-scale PV generators in meeting the economic and technical challenges.

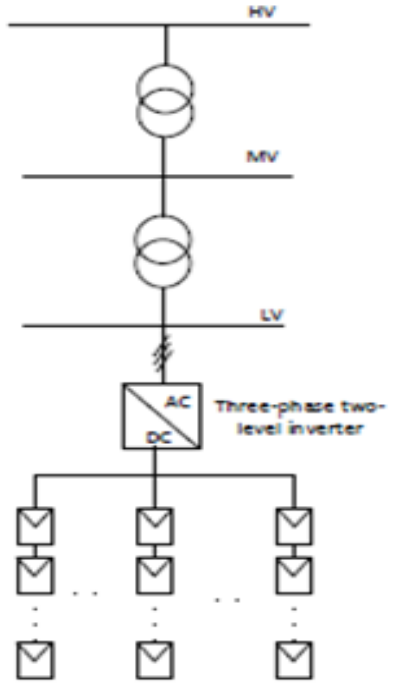

(a)

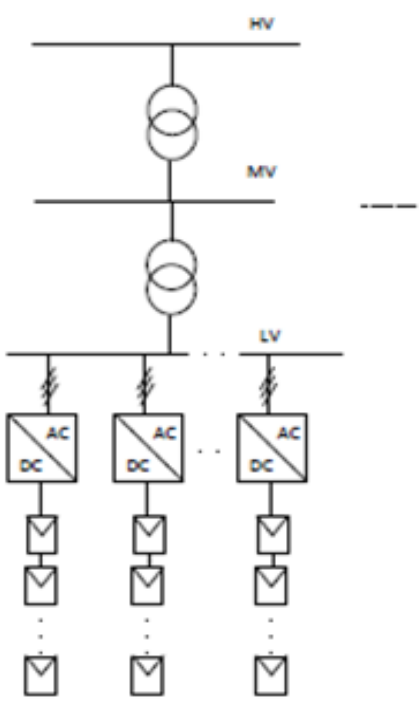

(b)

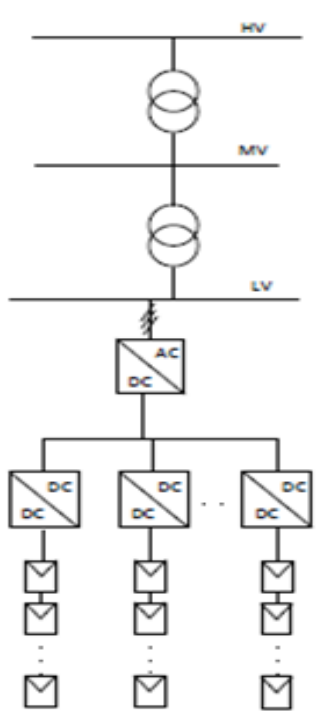

(c)

Figure 8. Utility-scale PV system architecture with connection of transformer at medium voltage.

(a) Centralised Inverter. (b) Decentralised multi-string inverters, i. Single-stage power conversion, ii. Twostage power conversion.

Moving forward, the authors opine that education and internalizing energy efficiency in homes and industries should be the first course of action before alternative generation from RE sources are employed with the aim to minimize greenhouse gas emissions from electricity generation. Subsequently, energy demands that are met by increasing utility-scale PV generation should be despatachable in terms of demand 
and supply. The bottleneck for utility-scale PV generation is, in the authors' view, the lack of a utility-scale energy storage system that can provide a so called "total solution" for RE. Therefore, research should be continuously focused on enhancing energy density, life-cycle, and cost effectiveness of static energy storage devices such as batteries. Althoug pump-hydro energy storage has been traditionally employe to effectively level the output power of intermittent energy sources like PV, a large land area requirement for pumpedhydro storage is impractical and costly, today. Research on improving energy density of supercapacitors will also be useful to mitigate the fast dynamic changes of PV output power. In the long term, power systems analysis should be conducted to understand the effects of energy storage systems on the grid so that regulations for utility-scale energy storage systems can be constructively devised in grid codes and standards.

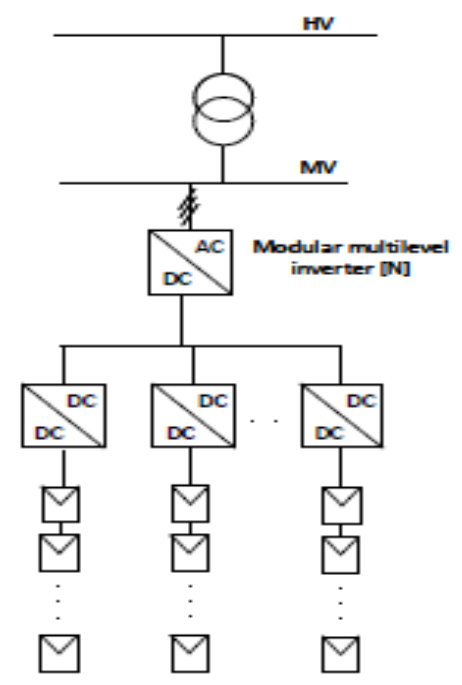

Figure 9. Utility-scale PV system based on a modular multilevel single-delta bridge-cell (SDBC) inverter connected directly to a medium-voltage bus.

\section{ACKNOWLEDGEMENTS}

The authors of this paper would like to acknowledge the support of Tenaga Nasional Research \& Development Fund (Seeding), under Project Code U-TS-RD-18-09. The content of this paper is purely for research and academic purpose, which in any circumstances does not represent the view of TNB and its subsidiaries.

\section{REFERENCES}

[1] REN 21 Steering Committee, "Renewables 2016 global status report", Renewable Energy Policy Network for the 21st Century, 2016.

[2] "Global market outlook for solar power 2017-2021", Solar Power Europe, Brussels, Belgium, 2018.

[3] D. Geibel, et. al., "Utility-scale PV systems: grid connection requirements, test procedures and European harmonisation", Photovoltaics International, vol. 4, May 2009.

[4] B. Weise, "Impact of K-factor and active current reduction during fault-ride-through of generating units connected via voltage-sourced converters on power system stability", IET Renewable Power Generation Journal, vol. 9, no. 1, pp. 25-36, Jan. 2015.

[5] "IEEE Standard for Interconnection and Interoperability of Distributed Energy Resources with Associated Electric Power Systems Interfaces". IEEE 1547-2018, The Institute of Electrical and Electronics Engineers, Inc.,New York, Apr. 2018.

[6] A. Cabrera-Tobar, et. al., "Review of advanced grid requirements for the integration of large scale photovoltaic power plants in the transmission system", Renew. Sustain. Energy Reviews, vol. 62, pp. 971-987, May 2016.

[7] "Global Wind Energy Outlook 2008", Global Wind Energy Council, Oct. 2008. [Online]. Available: http://gwec:net/publications/globalwind-energy-outlook/gweo-2008/

[8] “PVPS Annual Report 2016”, IEA PVPS, 2016. [Online]. Available: http://www.iea-pvps.org

[9] "Peninsular Malaysia electricity supply outlook 2017“, Energy Commission, Malaysia, Aug. 2017. [Online]. Available: https://www.st.gov.my 
[10] N. Longman, “Top 10 solar-producing countries", Energy Digital, May 2017. [Online]. Available http://www.energydigital.com/renewableenergy/top-10-solar-producing-countries

[11] "12 countries leading the way in renewable energy", Click Energy, Aug. 2017. [Online]. Available https://www.clickenergy.com.au/newsblog/12-countries-leading-the-way-in-renewable-energy

[12] "Egypt - Renewable Energy-export.gov", Export.gov, 2017. [Online]. Available: https://www.export.gov

[13] A. Jager-Waldau, "PV status report 2017", European Commission JRC Science for Policy Report, Luxemborg, European Union, 2017. [Online]. Available: http://publications.jrc.ec.europa.eu

[14] M. Gianni, "PV market, business and price developments in Italy", Gestore Servizi Energetici, 2017. [Online]. Available: https://www.gse.it

[15] "Trends in Photovoltaic Applications 2016", IEA-PVPS, 2016. [Online]. Available: http://www.ieapvps.org

[16] "World energy outlook 2017 China : Key findings", International Energy Agency, 2017. [Online]. Available: https://www.iea.org/weo/china/

[17] "Status of renewable energies in Japan", Institute for Sustainable Energy Policies, 2017. [Online]. Available: https://www.isep.or.jp/en

[18] "Energy policies of IEA countries", International Energy Agency, 2016. [Online]. Available: https://www.iea.org

[19] Fraunhofer ISE. "Net installed electricity generation capacity in Germany in 2018“. 2018. [Online]. Available: https://www.energycharts.de

[20] A. Etxegarai, et. al., "Review of grid connection requirements for generation assets in weak power grids", Renewable and Sustainable Energy Reviews, vol. 41, pp. 1501-1514, Jan. 2015.

[21] VDE-AR-N 4120:2015-01: "Technical requirements for the connection and operation of customer installations to the high-voltage network (TCC High-Voltage) ", National Grid Electricity Transmission, Germany, Oct. 2015.

[22] The Grid Code, Issue 5, "Revision 21, National Grid Electricity Transmission", United Kingdom, Mar. 2016.

[23] Technical Rules, "Western Power", Australia, Dec. 2011.

[24] "Technical regulation 3.2.2 for PV power plants above 11 kW", Energinet, Denmark, July 2016.

[25] "Solar Energy Plants Grid Connection Code", Egypt ERA, Egypt, Mar. 2017.

[26] Energy Commission Malaysia. "The Malaysian grid and distribution codes", 2016. [Online]. Available: http://www.tnb.com.my/business/malaysian-grid-code.html

[27] Energy Commission Malaysia. "Guidelines on large scale solar photovoltaics plant for connection to electricity networks [Electricity supply act 1990 (Act 447)]”, Feb. 2017. [Online]. Available: https://www.st.gov.my

[28] "IEEE recommended practice and requirements for harmonic control in electric power systems", IEEE Standards, 519-2014, pp. 1-29, June. 2014.

[29] A. Richter, et. al., "Transformer suitability for a successful load shedding in the TSO control area", International ETG Congress, Bonn, Germany, Nov. 2015, pp. 186-191.

[30] C. Rahmann, and A. Castillo, "Fast frequency response capability of Photovoltaic power plants: The necessity of new grid requirements and definitions", Energies, vol. 7, pp. 6306-6322, Sept. 2014.

[31] R. Amirante, et. al, "Overview on recent developments in energy storage: Mechanical, electrochemical and hydrogen technologies", Elsevier J. Energy Conversion and Management, vol. 132, pp. 372-387, Jan. 2017.

[32] E. Serban, et. al., "Voltage and frequency grid support strategies beyond standards", IEEE Trans. on Power Electron., vol. 32, no. 1, Jan. 2017.

[33] A. Al-Shetwi, et. al., "A review of the fault ride through requirements in different grid codes concerning penetration of PV system to the electric power network", ARPN J. Engineering and Applied Science, vol. 10, no. 21, pp. 9906-9912, Nov. 2015.

[34] B. Craciun, et. al, "Overview of recent grid codes for PV power integration", in Proc. 13th Int. Conf. Optimization of Electrical and Electronic Equipment (OPTIM), Brasov, Romania, May 2012, pp. 959-965.

[35] A. Basit, et. al., "A Review of grid requirements for wind farm in Denmark and China", presented at China Wind Power 2012, Beijing, China, Nov. 2012.

[36] Australian Energy Market Operator (AEMO). (2017, Mar.). "Black system South Australia 28 September 2016". [Online]. Available: https://www.aemo.com.au

[37] H. Berndt, et. al., "Transmission Code 2007: Network and System Rules of the German Transmission System Operators", Verbandder Netzbetreiber-VDN-e.V. beim VDEW, Germany. [Online]. Available: https://www.vde.com

[38] VDE. "Forum on Network Technology/Network Operation (2017, May)“. Summary of the Draft VDE-AR-N 4120:201705. [Online]. Available: https://www.vde.com

[39] M. Tsili and S. Papathanassiou, "A review of grid code technical requirements for wind farms", IET Renewable Power Generation, vol. 3, no. 3, pp. 308-332, Sept. 2009.

[40] N. Ullah and T. Thiringer, "Variable speed wind turbines for power system stability enhancement", IEEE Trans. Energy Convers., vol. 22, no. 1, pp. 52-60, Mar. 2007.

[41] N. Ullah, et. al. , "Voltage and transient stability support by wind farms complying with the E.ON Netz grid code", IEEE Trans. Power Syst., vol. 22, no. 4, pp. 1647-1656, Nov. 2007.

[42] S. Muyeen, et al. , "Low voltage ride through capability enhancement of wind turbine generator system during network disturbance", IET Renewable Power Generation, vol. 3, no. 1, pp. 65-74, Dec. 2008.

[43] S. Muyeen, et. al. " A variable speed wind turbine control strategy to meet wind farm grid code requirements", IEEE Trans. Power Syst., vol. 25, no. 1, pp. 331-340, Feb. 2010.

[44] Z. Chen, et. al. , "A review of the state of the art of power electronics for wind turbines", IEEE Trans. Power Electron., vol. 24, no. 8, pp. 1859-1875, Aug. 2009.

[45] I. Erlich and F. Shewarega, "Grid codes in power systems with significant renewable-based generation", in Smart Grid Handbook, 1st ed., vol. 1, West Sussex: John Wiley \& Sons, Aug. 2016, pp. 322-332. 
[46] J. Niiranen, et. al., "Low-voltage ride-through testing of wind turbine converters at ABB helps wind turbines meet the requirements of IEC61400-21 more quickly". ABB Press Release, Apr. 2009. [Online]. Available: http://www.abb.com

[47] T. Neumann, et. al. , "Enhanced dynamic voltage control of Type 4 wind turbines during unbalanced grid faults", IEEE Trans.Energy Convers., vol. 30, no. 4, pp. 1650-1659, Dec. 2015.

[48] P. Denholm, et. al. , "On the path to SunShot: Emerging issues and challenges in integrating high levels of solar into the electrical generation and transmission system", NREL, 2016. [Online]. Available: http://www.nrel.gov

[49] G. Lammert, et. al. , "Modelling and dynamic performance of inverter based generation in power system studies: an international questionnaire survey", CIRED - Open Access Proc. Journal, vol. 2017, no. 1, pp. 1899-1902, 2017.

[50] A. Anzalchi and A. Sarwat, "Overview of technical specifications for grid-connected photovoltaic systems", Energ. Conver. Manage., vol. 152, pp. 312-327, Oct. 2017.

[51] Nur I. Zolkifri, et. al, "Performance analysis of Malaysian low voltage distribution network under different solar variability days," Indonesian J. Elec. Eng. \& Com. Sci., vol. 13, no. 3, pp. 1152-1160, Mar. 2019.

[52] J. Antonanzasa, et. al., "Review of photovoltaic power forecasting", Solar Energy, vol. 136, pp. 78-111, Oct. 2016.

[53] P. Ochsner, et. al. , "Spatial modelling of grid connected PV plants with $3 D$ irradiance values", $28^{\text {th }}$ European Photovoltaic Solar Energ. Conf. and Exhibition, Paris, France, Sept./Oct. 2013, pp. 3597-3600.

[54] M. Tamaki, et. al. , "Development of PCS for battery system installed in megawatt photovoltaic system", 15 th Int. Power Electron. and Motion Control Conf., EPE-PEMC 2012, Novi Sad, Serbia, Sept. 2012, pp. 1-4.

[55] S. Vavilapalli, et. al. , "Design and real-time simulation of an AC voltage regulator based battery charger for largescale PV-grid energy storage systems", IEEE Access, vol. 5, pp. 25158-25170, Dec. 2017.

[56] A. Cabrera-Tobar, et. al. , "Topologies for large scale photovoltaic power plants", Renew. Sustain. Energy Reviews, vol. 59, pp. 309-319, Jan. 2016.

[57] S. B. Kjaer, et. al. , "A review of single-phase grid-connected inverters for photovoltaic modules", IEEE Trans. Ind. Appl., vol. 41, no. 5, pp. 1292-1306, Sept./Oct. 2005.

[58] T. Kerekes, et. al. , "An optimization method for method for designing large PV plants", IEEE J. Photovoltaics, vol. 3, no. 2, pp. 814-822, Apr. 2013.

[59] "Demand response and energy efficiency roadmap: maximizing preferred resources". Folsom, California: California Independent System Operator; 2013.

[60] M. Obi and R. Bass, "Trends and challenges of grid-connected photovoltaic systems-A review, Renew. Sustain. Energy Reviews, vol. 58, pp. 1082-1094, May 2016.

[61] W. Omran, et. al. , "Investigation of methods for reduction of power fluctuations generated from large grid-connected photovoltaic systems", IEEE Trans. Energ. Convers., vol. 26, no. 1, pp. 318-327, Mar. 2011.

[62] Ameerul A. J. Jeman, et. al. , "Fault analysis for renewable energy power system in micro-grid distributed generation", Indonesian J Elec. Eng. \& Com. Sci, vol. 13, no. 3, pp. 1117-1123, Mar. 2019.

[63] X. Yuan, et. al. , "An improved method of instantaneous symmetrical components and its detection for positive and negative sequence current", in Proc. of CSEE 2008, vol. 28(1), pp. 52-58, Jan. 2008.

[64] R. Inzunza, et. al. , "Development of a 1500Vdc photovoltaic inverter for utility-scale PV power plants", IEEE 2nd Int. Future Energy Electron. Conf. (IFEEC), Taiwan, Nov. 2015, pp. 1-4.

[65] P. Sochor, et. al. , "Low-voltage-ride-through control of a modular multilevel single-delta bridge-cell (SDBC) inverter for utility-scale photovoltaic systems", IEEE Trans. Ind. Appl., vol. 54, no.5, pp. 4739-4751.

[66] M. R. Maghamiab, et. al. , "Power loss due to soiling on solar panel: A review", Renew. Sustain. Energy Reviews, vol. 59, pp. 1307-1316, Jun. 2016.

[67] P. Sochor and H. Akagi, "Theoretical comparison in energy-balancing capability between star- and deltaconfigured modular multilevel cascade inverters for utility-scale photovoltaic systems", IEEE. Trans. Power Electron., vol. 31, no. 3, pp. 1980-1992 Mar. 2016.

[68] Y. Yu, et. al. , "Power balance of cascaded H-bridge multilevel converters for large-scale photovoltaic integration", IEEE Trans. Power Electron., vol. 31, no. 1, pp. 292-303, Jan. 2016.

[69] H. Choi, et. al. , "Large-scale PV system based on the multiphase isolated DC/DC converter", $3^{\text {rd }}$ IEEE Int. Symp. on Power Electrons. Distributed Generation Systems (PEDG), Aalborg, Denmark, Jun. 2012, pp. 801-807.

\section{BIOGRAPHIES OF AUTHORS}

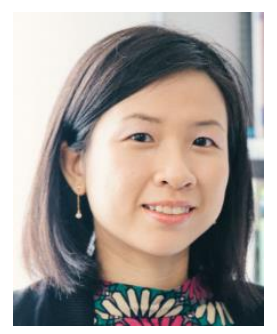

Nadia Tan Mei Lin received the B.Eng. (Hons.) degree from the University of Sheffield, Sheffield, U.K., in 2002, the M. Eng. degree from Universiti Tenaga Nasional (UNITEN), Kajang, Malaysia, in 2007, and the Ph.D. degree from Tokyo Institute of Technology, Tokyo, Japan, in 2010, all in electrical engineering. Since April 2017, she has been an Associate Professor in the Department of Electrical and Electronics Engineering, UNITEN. Her research interests include power conversion systems for energy storage, bidirectional isolated $\mathrm{dc}-\mathrm{dc}$ converters, multilevel cascaded inverters for renewable energy applications and power systems stability. She is a Chartered Engineer registered with Engineering Council, United Kingdom, a Member of the Institution of Engineering and Technology (IET) and the Institute of Electrical and Electronics Engineers (IEEE), and a Graduate Member of the Institution of Engineers Malaysia (IEM). 

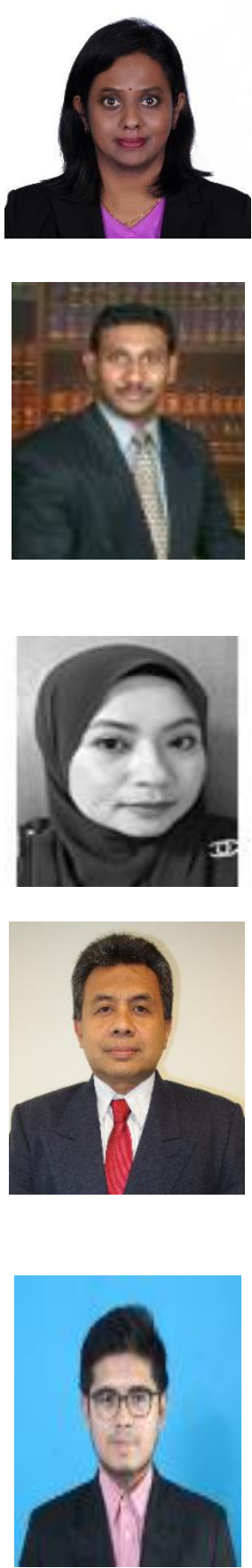

Agileswari K. Ramasamy received her B.Sc (Engineering) degree from Purdue University, USA in 1995. She obtained her MSc. (Control System) from Imperial College, London in 2001 and $\mathrm{PhD}$ in Electrical Engineering from Universiti Tenaga Nasional (UNITEN). She is currently an Associate Professor in the Department of Electrical and Electronics Engineering at UNITEN and is serving as a Deputy Dean of Research and Postgraduate in the College of Engineering, UNITEN. She is also a Chartered Member of the Institution of Engineering and Technology (IET). She is currently active in research and consultancy in control system, power system, power quality, energy efficiency and renewable energy.

Vigna K. Ramachandaramurthy received the Ph.D. degree in electrical engineering from the University of Manchester Institute of Science and Technology in 2001. He is currently a Professor with the Institute of Power Engineering, Universiti Tenaga Nasional (UNITEN). His area of interest includes power systems related studies, renewable energy, energy storage, power quality, electric vehicle, and rural electrification. Dr. Vigna has served as the IET Malaysia Chairman, an IET Council Member, an Institution of Engineers Malaysia (IEM) Council Member, IET Younger Members Board representing West Asia, an International Professional Registration Advisor, an Interviewer, and a Convenor for Chartered Engineering (U.K.) in Malaysia. He is also a Chartered Engineer registered with the Engineering Council of U.K., and a Professional Engineer registered with the Board of Engineers, Malaysia.

Marayati Binti Marsadek received the B.Eng (Hons.) degree in Electric Power Engineering in 2002 and M. Eng degree in Electrical Engineering in 2006 from Universiti Tenaga Nasional. She was awarded with the Ph.D degree in Electrical, Electronics and System Engineering from the National University of Malaysia, in 2011. She is currently the Director of Institute of Power Engineering (IPE) and a Senior Lecturer in the Department of Electric Power Engineering at Universiti Tenaga Nasional. Her research interest includes power system stability, active network management and risk assessment.

Ridzal Bin Othman received the B.Eng (Hons) degree in Electronic \& Electrical Engineering from Loughborough University of Technology, Loughborough, England in 1993. He received his Ph.D. degree in the same field and at the same universityin 1999. Now he works for Malaysia's premier power utility, Tenaga Nasional Berhad. From 1999 to 2005, he was a Researcher at TNB Research Sdn. Bhd. where he was actively involved in real-time digital simulation and dynamic performance testing of protective relays. He was assigned to Engineering Department of Transmission Division in 2005 to work on protection coordination, insulation coordination and other engineering studies until 2017. He is currently responsible for new implementation of grid-related technology under Grid Solution Expertise Department. Since 2007 , he is the Secretary of CIGRE Malaysia.

Ibrahim Ariffin received the Bachelor of Science in Electrical Power Engineering from Renssalaer Polytechnic Institute, NY, USA in 2008. From 2008 to 2013, he was a Grid Planner with Tenaga Nasional Berhad (TNB), managing the future development of $275 \mathrm{kV}$ and $500 \mathrm{kV}$ networks. Since 2014, he joined the Technical Studies Unit of Transmission Division at TNB as a Senior Engineer where he is responsible to ensure compliance of new power plants in meeting the Malaysian Grid Code's requirement via simulation studies and on-site testing. Mr. Ibrahim is a member of the Board of Engineers Malaysia. He is also a member of the ASEAN Generation \& Transmission Planning Taskforce - a milestone towards the realization of ASEAN Power Grid. 